\title{
Plant and animal protein intake and its association with overweight and obesity among the Belgian population
}

\author{
Yi Lin ${ }^{1}$, Selin Bolca ${ }^{2}$, Stefanie Vandevijvere ${ }^{3}$, Stephanie De Vriese ${ }^{4}$, Theodora Mouratidou ${ }^{5}$, \\ Melissa De Neve ${ }^{1}$, Anja Polet ${ }^{1}$, Herman Van Oyen ${ }^{3}$, John Van Camp ${ }^{6}$, Guy De Backer ${ }^{1}$, \\ Stefaan De Henauw ${ }^{1,7}$ and Inge Huybrechts ${ }^{1 *}$ \\ ${ }^{1}$ Unit of Nutrition and Food Safety, Department of Public Health, Faculty of Medicine and Health Sciences, Ghent University, \\ UZ - 2 Blok A, De Pintelaan 185, B-9000 Ghent, Belgium \\ ${ }^{2}$ Laboratory of Microbial Ecology and Technology, Faculty of Bioscience Engineering, Ghent University, Coupure Links 653, \\ B-9000 Ghent, Belgium \\ ${ }^{3}$ Unit of Epidemiology, Scientific Institute of Public Health, Juliette Wytsmanstraat 14, B-1050 Brussels, Belgium \\ ${ }^{4}$ Alpro Foundation vzw, Vlamingstraat 28, 8560 Wevelgem, Belgium \\ ${ }^{5}$ GENUD (Growth, Exercise, NUtrition and Development) Research Group, University of Zaragoza, C/Corona de Aragon 42, \\ 50009 Zaragoza, Spain \\ ${ }^{6}$ Department of Food Safety and Food Quality, Ghent University, Coupure Links 653, B-9000 Ghent, Belgium \\ ${ }^{7}$ Department of Nutrition and Dietetics, Faculty of Health Care Vesalius, University College Ghent, Keramiekstraat 80, \\ B-9000 Ghent, Belgium
}

(Received 18 May 2010 - Revised 23 September 2010 - Accepted 14 October 2010 - First published online 9 December 2010)

\begin{abstract}
The objective of the present study was to assess animal and plant protein intakes in the Belgian population and to examine their relationship with overweight and obesity (OB). The subjects participated in the Belgian National Food Consumption Survey conducted in 2004. Food consumption was assessed by using two non-consecutive $24 \mathrm{~h}$ dietary recalls. About 3083 participants ( $\geq 15$ years of age; 1546 males, 1537 females) provided completed dietary information. Animal protein intake ( $47 \mathrm{~g} / \mathrm{d})$ contributed more to total protein intakes of $72 \mathrm{~g} / \mathrm{d}$ than plant protein intake, which accounted for $25 \mathrm{~g} / \mathrm{d}$. Meat and meat products were the main contributors to total animal protein intakes (53\%), whereas cereals and cereal products contributed most to plant protein intake (54\%). Males had higher animal and plant protein intakes than females $(P<0 \cdot 001)$. Legume and soya protein intakes were low in the whole population $(0 \cdot 101$ and $0 \cdot 174 \mathrm{~g} / \mathrm{d}$, respectively). In males, animal protein intake was positively associated with BMI $(\beta=0.013 ; P=0 \cdot 001)$ and waist circumference (WC; $\beta=0 \cdot 041$; $P=0 \cdot 002$ ). Both in males and females, plant protein intake was inversely associated with BMI (males: $\beta=-0 \cdot 036 ; P<0 \cdot 001$; females: $\beta=-0.046 ; P=0.001$ ) and WC (male: $\beta=-0.137 ; P<0.001$; female: $\beta=-0.096 ; P=0.024$ ). In conclusion, plant protein intakes were lower than animal protein intakes among a representative sample of the Belgian population and decreased with age. Associations with anthropometric data indicated that plant proteins could offer a protective effect in the prevention of overweight and OB in the Belgian population.
\end{abstract}

\section{Key words: Animal protein: Plant protein: BMI: Waist circumference: Obesity}

In recent decades, intakes of dietary protein have been associated with treating chronic diseases such as obesity (OB) and CVD besides improving health outcomes ${ }^{(1,2)}$. Evidence indicates that a high dietary protein intake decreases the risk of non-communicable diseases via the regulation of energy intake, increment of satiety, lowering of systolic and diastolic blood pressure, decrement of total cholesterol levels and presence of LDL-cholesterol and $\mathrm{TAG}^{(3-5)}$. In addition, high protein intakes are associated with the prevention of the development of chronic diseases, including $\mathrm{OB}$, the metabolic syndrome, CVD, type 2 diabetes, osteoporosis, and breast and prostate cancer ${ }^{(3,6-10)}$.

Findings from recent randomised controlled trials relate plant proteins to health benefits more than animal proteins $^{(11-19)}$, mainly due to factors affecting the level of hypercholesterolaemic amino acids present in plant proteins ${ }^{(20)}$. However, the debate on the potential health effects of animal protein- and plant protein-rich diets is

Abbreviations: OB, obesity; OW, overweight; WC, waist circumference.

*Corresponding author: Dr I. Huybrechts, fax +329332 4994, email inge.huybrechts@ugent.be 
still ongoing. For instance, some studies have reported a positive association between animal protein intakes and the risk of chronic diseases ${ }^{(21-24)}$, whereas others have indicated an inverse relationship ${ }^{(25-27)}$. One of these trials, involving healthy menopausal women, has suggested that milk whey protein can prevent bone loss ${ }^{(25)}$, while two others trials with overweight (OW) or insulin-resistant subjects have indicated that proteins from meat, poultry, fish and dairy foods had beneficial metabolic effects ${ }^{(26,27)}$ and improved insulin sensitivity ${ }^{(26,27)}$.

In Belgium, information on plant and animal protein intakes of the population is still lacking until now. Therefore, the present study aims (1) to estimate the intake levels of animal and plant proteins in a representative sample of the Belgian population and (2) to examine their associations with $\mathrm{OW}$ and $\mathrm{OB}$ measured by BMI and waist circumference (WC).

\section{Methodology}

\section{Study design and data collection}

The Belgian National Food Consumption Survey ${ }^{(28)}$ was performed in 2004 following largely the recommendations of the European Food Consumption Survey Method project ${ }^{(29)}$. More details on the survey can be found elsewhere $^{(28)}$. Belgian national citizens aged 15 years or older, residing in private households in Belgium, were eligible to participate in the national survey. The population was stratified by sex and in four age groups (15-18, 19-59, 60-74 and $\geq 75$ years). Approximately 400 individuals were allocated in each sex-age group. Participants were selected from the national register using a multi-stage stratified sampling procedure. Institutionalised individuals, not able to speak one of the national languages or physically or mentally unable to be interviewed, were excluded from the survey. In total, 7543 individuals were invited to participate.

The present study was conducted according to the guidelines laid down in the Declaration of Helsinki and approved by the medical ethical committee of the Scientific Institute of Public Health, Brussels. Written or verbal informed consent was obtained from all subjects. Verbal consent was witnessed and formally recorded.

\section{Dietary intake assessment}

Two repeated, non-consecutive $24 \mathrm{~h}$ dietary recall interviews were used to collect information on each participant's food consumption. The first $24 \mathrm{~h}$ recall was obtained through a computer-assisted personal interview during a home visit by a trained dietitian. The second $24 \mathrm{~h}$ recall was performed 2-8 weeks later during a second home visit (median 3 weeks). Interviews were randomly allocated to different days of the week and over a 12-month period in an effort to reduce within-person variation and to avoid seasonality effects. The $24 \mathrm{~h}$ recalls collected information on the types and quantities of foods and beverages consumed over the preceding day to the interview.

The dietitians used European Prospective Investigation into Cancer and Nutrition software (EPIC-SOFT; International Agency for Research on Cancer (IARC), Lyon, France) to obtain standardised $24 \mathrm{~h}$ recall interviews. EPIC-SOFT was designed to obtain a detailed description and quantification of all foods and beverages consumed in a standardised way ${ }^{(30)}$. Quantification was facilitated using a picture book with coloured photographs describing foods of different portion sizes ${ }^{(28)}$.

Animal and plant protein contents were estimated using the Belgian food composition table NUBEL ${ }^{(31)}$, the Dutch food composition database $\mathrm{NEVO}^{(32)}$ and the USDA food composition guidelines ${ }^{(33)}$. In the present study, consumption of soya products was analysed separately from the legumes food group because of their potential health effects. The US Food and Drug Administration ${ }^{(34)}$ approved that a daily consumption of soya protein can prevent chronic diseases.

In the present study, four and six main food groups, respectively, contributed most to the animal and plant protein intakes. The four main food groups contributing to the levels of animal protein intake were dairy products, meat and meat products, fish and shellfish, and eggs and egg products. Dairy products included milk, milk beverages (including cream desserts and puddings (milk-based), dairy and non-dairy creams, milk for coffee, and creamers), yogurt, fromage blanc and petits suisses and cheeses (including fresh cheeses). The group of meat and meat products included fresh meat (beef, veal, pork and lamb), poultry and game (chicken, turkey, duck and rabbit), and processed meat, whereas the group of fish and shellfish represented all fish, crustaceans, molluscs, fish products and fish in crumbs. Eggs were the most important item in the egg and egg products group.

Plant proteins were derived mainly from potatoes and other tubers, vegetables, legumes, fruits, nuts and seeds, cereal and cereal products, and soya products. The group of potatoes and other tubers consisted mainly of potatoes. Vegetables included leafy vegetables, fruiting vegetables such as tomato and pumpkin, root vegetables, cabbages, mushrooms, grain and pod vegetables, onions, garlic, stalk vegetables and sprouts, mixed salad and mixed vegetables. Soyabeans and derived products were excluded from the legumes group and were classified as a separate group. Fruits referred to all fruits, including fresh fruits (fruits, mixed fruits and olives) and nuts and seeds. Cereals and cereal products included mainly flour, flakes, starches, semolina, pasta, rice, other grains, breakfast cereals, bread, crisp bread, rusks, salty biscuits, aperitif biscuits and dough and pastry.

\section{Anthropometric measurements}

Weight (kg) and height $(\mathrm{m})$ were self-reported. WC was measured by a trained dietitian at home while participants 
were standing upright (upper clothes were raised to enable measurement of WC on the skin or underwear). Pregnant women reported pre-gestational weights. BMI was calculated as weight $(\mathrm{kg}) /$ height $\left(\mathrm{m}^{2}\right)$. Adult participants were allocated to four BMI categories according to the cut-off criteria of the $\mathrm{WHO}^{(35)}$ for adult BMI: underweight $\left(<18.5 \mathrm{~kg} / \mathrm{m}^{2}\right)$; normal weight $\left(18.5-24.9 \mathrm{~kg} / \mathrm{m}^{2}\right)$; OW $\left(25.0-29.9 \mathrm{~kg} / \mathrm{m}^{2}\right)$; obese $\left(\geq 30 \cdot 0 \mathrm{~kg} / \mathrm{m}^{2}\right)$. Adolescent participants were classified into four similar BMI categories based on the Flemish cut-off values ${ }^{(36)}$ for underweight. Cut-off points for normal weight, OW and obese were based on the criteria proposed by Cole et $a{ }^{(37)}$. For adult WC, sex-specific cut-off criteria were used ${ }^{(38)}$. For males, $<94 \mathrm{~cm}$ was defined as normal, $94-102 \mathrm{~cm}$ as normal to borderline, $\geq 102 \mathrm{~cm}$ as high risk of $\mathrm{OW}$ and obese (referred to as 'too large' in Table 1). For females, $<80 \mathrm{~cm}$ was defined as normal, $80-88 \mathrm{~cm}$ as normal to borderline, $\geq 88 \mathrm{~cm}$ as high risk of OW and obese. The cut-off criteria of adolescent WC were based on Taylor et al. ${ }^{(39)}$.

\section{Statistical analyses}

The Statistical Package for the Social Sciences for Windows version 15 (SPSS, Inc., Chicago, IL, USA) was used to perform descriptive and statistical analyses. Descriptive statistics are presented in the sex-age-specific groups as means with their standard errors. Total energy, total protein, animal and plant protein intake and percentage of energy intake (Table 2) were normally distributed, whereas animal and plant protein intakes from food groups (Tables 3 and 4, respectively) were skewed. Student's $t$ test, ANOVA with Bonferroni correction and the Mann-Whitney $U$ test were used to examine statistically significant differences, with a two-tailed significance level set at $0 \cdot 05$.

Multiple linear regression analysis (generalised linear model) by the sex-age strata was used to evaluate the association between BMI, WC and animal and plant protein intakes. Each model included BMI and $\mathrm{WC}$ as separate dependent variables, animal and plant protein as covariates and age as the factor variable. Interactions were tested, and the significance level was estimated by type 3 Wald $\chi^{2}$ test.

\section{Results}

Individuals who provided two $24 \mathrm{~h}$ dietary recall interviews with valid information were included in the analysis $(3083$ out of a total of 7543). Male ( $n$ 1546) participants had a mean of $25 \mathrm{~kg} / \mathrm{m}^{2}$ for BMI and a mean of $88 \mathrm{~cm}$ for WC. In total, $34 \%$ of the males were defined as OW, $10 \cdot 1 \%$ as obese and $29 \%$ had a too large WC. Mean BMI for female ( $n$ 1537) participants was $24 \mathrm{~kg} / \mathrm{m}^{2}$, and mean WC was $80 \mathrm{~cm}$. In total, $25 \%$ of the females were defined as OW, $10 \cdot 5 \%$ as obese and $42 \%$ had a too large WC (Table 1 ).

Most of the participants in the older categories were categorised as OW or obese (60-75 years: $63 \%$; $\geq 75$ years: $50 \%)$ and with borderline or too large WC (60-75 years: $80 \%$; $\geq 75$ years: $81 \%$ ).

\section{Total protein, animal protein and plant protein intakes}

Total protein intakes $(1 \cdot 2 \mathrm{MJ} / \mathrm{d})$ contributed $15.4 \%$ to the total energy intakes of the population. Animal protein intakes contributed most and delivered a mean energy intake of $0.795 \mathrm{MJ} / \mathrm{d}$. Animal protein intake $(47 \mathrm{~g} / \mathrm{d}$, range $0 \cdot 030-222 \mathrm{~g} / \mathrm{d}$ ) was the main contributor $(64 \%)$ to the total protein intakes (mean $72 \mathrm{~g} / \mathrm{d}$ ), while plant protein intake accounted for $25 \mathrm{~g} / \mathrm{d}$ (range $2 \cdot 4-83 \mathrm{~g} / \mathrm{d}$ ). The total protein intakes of the present study population were in line with the WHO/FAO/United Nations University recommendations (i.e. $10 \cdot 0-15 \cdot 0 \%$ of the total energy intake) $^{(40)}$ (data not shown).

Total protein, animal protein and plant protein intakes were significantly higher in males than in females (Table 2). Percentage energy contributions from the total protein and animal protein intakes were significantly lower in male and in female adolescents than in the older age groups. The contribution of plant proteins to

Table 1. BMI and waist circumference (WC) measurements of subjects participating in the Belgian National Food Consumption Survey (Mean values with their standard errors, $n$ 3083)

\begin{tabular}{|c|c|c|c|c|c|c|c|c|c|c|c|c|}
\hline & \multirow[b]{2}{*}{$n$} & \multicolumn{6}{|c|}{$\mathrm{BMI}^{*}$} & \multicolumn{5}{|c|}{$W C^{*}$} \\
\hline & & $\begin{array}{l}\text { Mean } \\
\left(\mathrm{kg} / \mathrm{m}^{2}\right)\end{array}$ & SEM & $\begin{array}{c}\text { Underweight } \\
(\%)\end{array}$ & $\begin{array}{c}\text { Normal wt } \\
(\%)\end{array}$ & $\begin{array}{l}\text { Overweight } \\
(\%)\end{array}$ & $\begin{array}{l}\text { Obese } \\
(\%)\end{array}$ & $\begin{array}{l}\text { Mean } \\
(\mathrm{cm})\end{array}$ & SEM & $\begin{array}{c}\text { Normal } \\
(\%)\end{array}$ & $\begin{array}{l}\text { Borderline } \\
(\%)\end{array}$ & $\begin{array}{c}\text { Too large } \\
(\%)\end{array}$ \\
\hline \multicolumn{13}{|l|}{ Sex } \\
\hline Males & 1546 & 25 & 0.1 & $3 \cdot 1$ & 52 & 34 & $10 \cdot 1$ & 88 & 0.7 & 43 & 27 & 29 \\
\hline Females & 1537 & 24 & 0.1 & $5 \cdot 7$ & 58 & 25 & 10.5 & 80 & 0.7 & 39 & 19 & 42 \\
\hline \multicolumn{13}{|c|}{ Age group (years) } \\
\hline $15-18$ & 762 & 21 & 0.1 & 9.7 & 79 & $10 \cdot 2$ & $1 \cdot 3$ & 76 & 0.6 & 72 & 20 & $7 \cdot 6$ \\
\hline $19-59$ & 828 & 24 & 0.2 & 3.7 & 60 & 26 & $10 \cdot 1$ & 81 & 1.0 & 51 & 24 & 25 \\
\hline $60-75$ & 789 & 26 & 0.2 & 1.0 & 36 & 44 & 18.6 & 91 & 0.9 & 20 & 27 & 53 \\
\hline$\geq 75$ & 704 & 25 & 0.2 & 3.2 & 46 & 40 & $10 \cdot 8$ & 90 & 1.2 & 19 & 22 & 59 \\
\hline
\end{tabular}

${ }^{*}$ Weighted mean of BMI and WC. 
Table 2. Total energy, total protein, animal and plant protein intake, and percentage of energy intakes of the survey participants

(Mean values with their standard errors, $n$ 3083)

\begin{tabular}{|c|c|c|c|c|c|c|c|c|c|}
\hline & \multicolumn{9}{|c|}{ Age group (years) } \\
\hline & \multicolumn{2}{|c|}{$15-18$} & \multicolumn{2}{|c|}{$19-59$} & \multicolumn{2}{|c|}{$60-74$} & \multicolumn{2}{|c|}{$\geq 75$} & \multirow[b]{2}{*}{$P \dagger$} \\
\hline & Mean & SEM & Mean & SEM & Mean & SEM & Mean & SEM & \\
\hline \multicolumn{10}{|c|}{ Total energy intake $(\mathrm{MJ} / \mathrm{d})^{\star \star}$} \\
\hline Males & $10 \cdot 5^{a}$ & 39 & $10 \cdot 3^{a}$ & 45 & $9 \cdot 0^{\mathrm{b}}$ & 32 & $8 \cdot 2^{c}$ & 31 & $<0.001$ \\
\hline Females & $7 \cdot 5^{\mathrm{a}}$ & 27 & $6 \cdot 9^{b}$ & 26 & $6 \cdot 6^{\mathrm{b}}$ & 25 & $6 \cdot 2^{c}$ & 23 & $<0.001$ \\
\hline \multicolumn{10}{|c|}{ Total protein $(\mathrm{g} / \mathrm{d})^{\star *}$} \\
\hline Males & $85^{\mathrm{a}}$ & 1.4 & $91^{\mathrm{b}}$ & 1.6 & $82^{\mathrm{a}}$ & $1 \cdot 2$ & $74^{\mathrm{c}}$ & $1 \cdot 1$ & $<0.001$ \\
\hline Females & $61^{\mathrm{a}}$ & 0.9 & $64^{\mathrm{a}}$ & 1.0 & $62^{\mathrm{a}}$ & 1.0 & $59^{\mathrm{b}}$ & $1 \cdot 1$ & 0.002 \\
\hline \multicolumn{10}{|c|}{ Animal protein $(\mathrm{g} / \mathrm{d})^{\star \star}$} \\
\hline Males & $52^{\mathrm{a}}$ & $1 \cdot 2$ & $61^{b}$ & 1.4 & $55^{\mathrm{a}}$ & 1.0 & $49^{c}$ & 0.9 & $<0.001$ \\
\hline Females & $37^{\mathrm{a}}$ & $0 . \overline{8}$ & $42^{b}$ & 0.8 & $42^{\mathrm{b}}$ & 0.8 & $40^{\mathrm{a}}$ & 0.9 & $<0.001$ \\
\hline \multicolumn{10}{|c|}{ Plant protein $(\mathrm{g} / \mathrm{d})^{\star *}$} \\
\hline Males & $30^{\mathrm{a}}$ & 0.6 & $30^{\mathrm{a}}$ & 0.6 & $27^{\mathrm{b}}$ & 0.5 & $25^{\mathrm{c}}$ & 0.5 & $<0.001$ \\
\hline Females & $24^{\mathrm{a}}$ & 0.4 & $22^{b}$ & 0.4 & $21^{\mathrm{c}}$ & 0.4 & $18 \cdot 8^{d}$ & 0.4 & $<0.001$ \\
\hline \multicolumn{10}{|c|}{ Energy intake (\%) } \\
\hline \multicolumn{10}{|c|}{ Total protein } \\
\hline Males & $13 \cdot 8^{a}$ & 0.2 & $15 \cdot 2^{b}$ & 0.2 & $15 \cdot 7^{b}$ & 0.2 & $15 \cdot 5^{\mathrm{b}}$ & 0.2 & $<0.001$ \\
\hline Females & $14 \cdot 0^{\mathrm{a}}$ & 0.2 & $16 \cdot 1^{b_{*}}$ & 0.2 & $16 \cdot 3^{b_{*}}$ & 0.2 & $16 \cdot 4^{b_{*}}$ & 0.3 & $<0.001$ \\
\hline \multicolumn{10}{|c|}{ Animal protein } \\
\hline Males & $8 \cdot 8^{a}$ & 0.2 & $10 \cdot 2^{b}$ & 0.2 & $10 \cdot 5^{b}$ & 0.2 & $10 \cdot 3^{b}$ & 0.2 & $<0.001$ \\
\hline Females & $8 \cdot 5^{\mathrm{a}}$ & 0.2 & $10 \cdot 6^{b}$ & 0.2 & $10 \cdot 9^{b}$ & 0.2 & $11 \cdot 2^{\mathrm{b} * \star}$ & 0.2 & $<0.001$ \\
\hline \multicolumn{10}{|l|}{ Plant protein } \\
\hline Males & $4.9^{a}$ & 0.1 & $5 \cdot 1^{\mathrm{a}}$ & 0.1 & $5 \cdot 2^{\mathrm{a}}$ & 0.1 & $5 \cdot 3^{b}$ & $0 \cdot 1$ & 0.014 \\
\hline Females & $5 \cdot 4^{\mathrm{a}}$ & 0.1 & $5 \cdot 6^{\mathrm{a} * *}$ & 0.1 & $5 \cdot 4^{a \star *}$ & 0.1 & $5 \cdot 2^{\mathrm{b}}$ & 0.1 & 0.004 \\
\hline
\end{tabular}

a,b,c,d Mean values within a row with unlike superscript letters were significantly different $(P<0.05$; ANOVA with Bonferroni correction) Mean values were significantly different between men and women: ${ }^{\star} P<0.05,{ }^{\star \star} P<0.001$ (Student's $t$ test).

$\dagger P$ value for mean differences between the sex-age groups (ANOVA).

the total energy intakes was higher in elderly males aged $\geq 75$ years and lowest in females aged $\geq 75$ years.

When examined by sex, total protein intakes were higher among adults (19-59 years) and lower among the elderly population $\geq 75$ years. Adult males (19-59 years) reported significantly higher animal protein intakes, while elderly males ( $\geq 75$ years) had the lowest. For female participants, on the other hand, animal protein intakes in the age groups of 19-59 years and 60-74 years were significantly higher than those in the other age groups. Plant protein intakes decreased with age in both sex groups, resulting in significant differences between the youngest and the oldest age groups ( $P<0.001$ for both).

\section{Main food groups}

Tables 3 and 4 show, respectively, the food groups contributing $57 \%$ to the total animal protein intakes (dairy products, meat and meat products, fish and shellfish, and egg and egg products) and $28 \%$ to the total plant protein intakes (potatoes and other tubers, vegetables, legumes (excluding soya products), soya products, fruits, and cereal and cereal products). Meat protein was the main contributor to the total protein intakes (34\%), with a mean intake of $26 \mathrm{~g} / \mathrm{d}$, followed by cereal protein $(19.3 \%)$, with a mean intake of $13.7 \mathrm{~g} / \mathrm{d}$, and dairy protein $(15.1 \%)$, with a mean intake of $11.0 \mathrm{~g} / \mathrm{d}$ (data not shown).
For both sexes, meat and meat products contributed most to the total animal protein intakes (males: 55\%, mean intake of $31 \mathrm{~g} / \mathrm{d}$; females: $50 \%$, mean intake of $21 \mathrm{~g} / \mathrm{d} ; \quad P<0.001$ ), followed by dairy products (males: $22 \%$, mean intake of $11.9 \mathrm{~g} / \mathrm{d}$; females: $26 \%$, mean intake of $10.0 \mathrm{~g} / \mathrm{d} ; P<0 \cdot 001$ ) (data not shown). Compared with males, females consumed less meat and dairy proteins derived from the above-mentioned food groups in general and their specific subgroups, except for yogurt. In particular, proteins from fresh and processed meat were consumed significantly less by females in all age groups (range of consumption: males and females, respectively: $14.3-18.2$ and $10 \cdot 2-11.6 \mathrm{~g} / \mathrm{d}$ for fresh meat; $7 \cdot 3-9 \cdot 2$ and $3 \cdot 9-5 \cdot 1 \mathrm{~g} / \mathrm{d}$ for processed meat; $P<0.001$ for both).

The elderly population ( $60-74$ or $\geq 75$ years) consumed less proteins derived from dairy and meat products compared with the other age groups. Female adolescents had significantly lower meat protein intakes than others $(18.9 \mathrm{~g} / \mathrm{d}$ contributing to $30 \%$ of the total animal protein intake). The elderly population (60-74 years) reported the lowest and the highest fish and shellfish protein intakes (males: $7.9 \%$, mean intake of $6.4 \mathrm{~g} / \mathrm{d}$; females: $6.7 \%$, mean intake of $4 \cdot 4 \mathrm{~g} / \mathrm{d}$ ). Protein intakes from eggs and egg products were not significantly different between the sex-age groups, with the exception of elderly females ( $\geq 75$ years) who had the lowest consumption among the sample. 
Table 3. Mean total animal protein intakes and intakes from main sources stratified by age (years) and sex (Mean values with their standard errors, $n$ 3083)

\begin{tabular}{|c|c|c|c|c|c|c|c|c|c|}
\hline \multirow[b]{3}{*}{ Animal protein food sources } & \multicolumn{4}{|c|}{ Contribution to animal protein intake $(\%)^{*}$} & \multicolumn{5}{|c|}{ Mean animal protein intake $(\mathrm{g} / \mathrm{d})^{*}$} \\
\hline & \multicolumn{2}{|c|}{ Males } & \multicolumn{2}{|c|}{ Females } & \multicolumn{2}{|c|}{ Males } & \multicolumn{2}{|c|}{ Females } & \multirow[b]{2}{*}{$P \dagger$} \\
\hline & Mean & SEM† & Mean & SEM† & Mean & SEM† & Mean & SEM† & \\
\hline \multicolumn{10}{|l|}{ Total animal protein } \\
\hline $15-18$ & $56^{\mathrm{a}}$ & 0.7 & $53^{a}$ & 0.7 & $49^{a}$ & $1 \cdot 2$ & $33^{a}$ & 0.8 & $<0.001$ \\
\hline $19-59$ & $58^{\mathrm{a}}$ & 0.7 & $57^{\mathrm{b}}$ & 0.6 & $54^{\mathrm{b}}$ & $1 \cdot 3$ & $37^{b}$ & 0.8 & $<0.001$ \\
\hline $60-74$ & $60^{\mathrm{b}}$ & 0.6 & $58^{b}$ & 0.6 & $49^{a}$ & $1 \cdot 0$ & $37^{b}$ & 0.8 & $<0.001$ \\
\hline$\geq 75$ & $58^{a}$ & 0.6 & $58^{b}$ & 0.7 & $43^{c}$ & 0.9 & $35^{a}$ & 0.8 & $<0.001$ \\
\hline \multicolumn{10}{|l|}{ Dairy products } \\
\hline $15-18$ & $15 \cdot 4^{\mathrm{a}}$ & 0.6 & $16 \cdot 8^{a}$ & 0.6 & $13 \cdot 5^{a}$ & 0.6 & $10 \cdot 4^{\mathrm{a}}$ & 0.4 & $<0.001$ \\
\hline $19-59$ & $14 \cdot 7^{\mathrm{a}}$ & 0.6 & $17 \cdot 2^{a}$ & 0.5 & $13 \cdot 4^{a}$ & 0.6 & $11 \cdot 1^{\mathrm{a}}$ & 0.4 & 0.027 \\
\hline $60-74$ & $13 \cdot 0^{\mathrm{b}}$ & 0.5 & $14 \cdot 6^{\mathrm{b}}$ & 0.5 & $10 \cdot 8^{b}$ & 0.5 & $9 \cdot 3^{b}$ & 0.4 & 0.112 \\
\hline$\geq 75$ & $13 \cdot 3^{b}$ & 0.5 & $15 \cdot 1^{\mathrm{b}}$ & 0.6 & $9 \cdot 8^{b}$ & 0.4 & $8 \cdot 9^{b}$ & 0.4 & 0.256 \\
\hline \multicolumn{10}{|l|}{ Milk } \\
\hline $15-18$ & $6 \cdot 2^{\mathrm{a}}$ & 0.4 & $6 \cdot 0^{\mathrm{a}}$ & 0.4 & $5 \cdot 6^{\mathrm{a}}$ & 0.4 & $3 \cdot 7^{\mathrm{a}}$ & 0.2 & $<0.001$ \\
\hline $19-59$ & $3 \cdot 1^{b}$ & $0 \cdot 2$ & $4 \cdot 1^{\mathrm{b}}$ & 0.3 & $2 \cdot 8^{\mathrm{b}}$ & $0 \cdot 2$ & $2 \cdot 7^{\mathrm{b}}$ & 0.2 & 0.841 \\
\hline $60-74$ & $2 \cdot 6^{\mathrm{b}}$ & 0.2 & $2 \cdot 9^{c}$ & 0.2 & $2 \cdot 1^{b}$ & 0.2 & $1 \cdot 8^{c}$ & 0.1 & 0.525 \\
\hline$\geq 75$ & $3 \cdot 3^{c}$ & $0 \cdot 2$ & $3 \cdot 8^{\mathrm{d}}$ & 0.3 & $2 \cdot 4^{\mathrm{b}}$ & 0.2 & $2 \cdot 2^{\mathrm{C}}$ & 0.2 & 0.454 \\
\hline \multicolumn{10}{|l|}{ Yogurt } \\
\hline $15-18$ & $1 \cdot 3^{\mathrm{a}}$ & 0.2 & $1 \cdot 8^{\mathrm{a}}$ & 0.2 & $1 \cdot 1^{\mathrm{a}}$ & 0.1 & $1 \cdot 1^{\mathrm{a}}$ & 0.1 & 0.058 \\
\hline $19-59$ & $1.9^{b}$ & 0.2 & $3 \cdot 1^{b}$ & 0.2 & $1 \cdot 7^{\mathrm{b}}$ & 0.2 & $2 \cdot 1^{\mathrm{b}}$ & 0.2 & 0.018 \\
\hline $60-74$ & $1 \cdot 5^{b}$ & 0.2 & $3 \cdot 2^{b}$ & 0.3 & $1 \cdot 4^{\mathrm{a}}$ & 0.2 & $2 \cdot 1^{\mathrm{b}}$ & 0.2 & $<0.001$ \\
\hline$\geq 75$ & $1 \cdot 7^{\mathrm{b}}$ & 0.2 & $2 \cdot 4^{\mathrm{a}}$ & 0.2 & $1 \cdot 3^{a}$ & 0.1 & $1 \cdot 5^{\mathrm{c}}$ & 0.2 & 0.173 \\
\hline \multicolumn{10}{|l|}{ Cheeses } \\
\hline $15-18$ & $7 \cdot 9^{a}$ & 0.4 & $9 \cdot 1^{\mathrm{a}}$ & 0.5 & $6 \cdot 7^{\mathrm{a}}$ & 0.4 & $5 \cdot 6^{a}$ & 0.3 & 0.160 \\
\hline $19-59$ & $9 \cdot 7^{b}$ & 0.5 & $10 \cdot 1^{b}$ & 0.4 & $8 \cdot 9^{b}$ & 0.5 & $6 \cdot 5^{\mathrm{b}}$ & 0.3 & 0.029 \\
\hline $60-74$ & $8 \cdot 9^{\mathrm{a}}$ & 0.5 & $8 \cdot 8^{a}$ & 0.4 & $7 \cdot 4^{\mathrm{a}}$ & 0.4 & $5 \cdot 5^{a}$ & 0.3 & 0.006 \\
\hline$\geq 75$ & $8 \cdot 3^{b}$ & 0.4 & $8 \cdot 9^{a}$ & 0.5 & $6 \cdot 1^{a}$ & 0.4 & $5 \cdot 2^{a}$ & 0.3 & 0.166 \\
\hline \multicolumn{10}{|l|}{ Meat and meat products } \\
\hline $15-18$ & $36^{a}$ & 0.9 & $30^{\mathrm{a}}$ & 0.9 & $31^{\mathrm{a}}$ & $1 \cdot 1$ & $18 \cdot 9^{\mathrm{a}}$ & 0.7 & $<0.001$ \\
\hline $19-59$ & $36^{a}$ & 0.9 & $32^{\mathrm{a}}$ & 0.8 & $34^{\mathrm{a}}$ & $1 \cdot 1$ & $21^{\mathrm{b}}$ & 0.8 & $<0.001$ \\
\hline $60-74$ & $37^{a}$ & 0.9 & $34^{b}$ & 0.9 & $31^{\mathrm{a}}$ & 0.9 & $22^{b}$ & 0.7 & $<0.001$ \\
\hline$\geq 75$ & $36^{a}$ & 0.9 & $36^{c}$ & $1 \cdot 0$ & $27^{\mathrm{b}}$ & 0.8 & $22^{b}$ & 0.7 & $<0.001$ \\
\hline \multicolumn{10}{|c|}{ Fresh meat (beef, veal, pork and lamb) } \\
\hline $15-18$ & $19 \cdot 2^{\mathrm{a}}$ & 0.8 & $15 \cdot 9^{a}$ & 0.9 & $16 \cdot 6^{a}$ & 0.8 & $10 \cdot 2^{\mathrm{a}}$ & 0.6 & $<0.001$ \\
\hline $19-59$ & $19 \cdot 3^{a}$ & 0.8 & $16 \cdot 1^{a}$ & 0.8 & $18 \cdot 2^{a}$ & 0.9 & $10 \cdot 7^{\mathrm{a}}$ & 0.6 & $<0.001$ \\
\hline $60-74$ & $19 \cdot 6^{a}$ & 0.8 & $17 \cdot 9^{a}$ & 0.8 & $16 \cdot 2^{\mathrm{a}}$ & 0.7 & $11 \cdot 4^{\mathrm{a}}$ & 0.5 & $<0.001$ \\
\hline$\geq 75$ & $19 \cdot 1^{a}$ & 0.8 & $19 \cdot 3^{b}$ & 0.9 & $14 \cdot 3^{b}$ & 0.7 & $11 \cdot 6^{\mathrm{b}}$ & 0.6 & 0.029 \\
\hline Poultry (chicken, duck, rab & d game) & & & & & & & & \\
\hline $15-18$ & $8 \cdot 1^{a}$ & 0.6 & $7 \cdot 5^{\mathrm{a}}$ & 0.6 & $7 \cdot 6^{a}$ & 0.7 & $4 \cdot 8^{a}$ & 0.4 & 0.086 \\
\hline $19-59$ & $7 \cdot 0^{\mathrm{a}}$ & 0.6 & $8 \cdot 1^{a}$ & 0.6 & $6 \cdot 6^{\mathrm{a}}$ & 0.6 & $5 \cdot 4^{\mathrm{a}}$ & 0.5 & 0.549 \\
\hline $60-74$ & $8 \cdot 0^{\mathrm{a}}$ & 0.6 & $7 \cdot 9^{a}$ & 0.6 & $6 \cdot 8^{a}$ & 0.6 & $5 \cdot 4^{\mathrm{a}}$ & 0.5 & 0.265 \\
\hline$\geq 75$ & $7 \cdot 5^{a}$ & 0.7 & $8 \cdot 9^{a}$ & 0.8 & $5 \cdot 6^{a}$ & 0.5 & $5 \cdot 5^{a}$ & 0.5 & 0.943 \\
\hline Processed meat & & & & & & & & & \\
\hline $15-18$ & $8 \cdot 4^{\mathrm{a}}$ & 0.4 & $6 \cdot 3^{a}$ & 0.4 & $7 \cdot 3^{a}$ & 0.4 & $3 \cdot 9^{a}$ & 0.2 & $<0.001$ \\
\hline $19-59$ & $9 \cdot 9^{b}$ & 0.5 & $7 \cdot 5^{a}$ & 0.4 & $9 \cdot 2^{b}$ & 0.5 & $4 \cdot 8^{a}$ & 0.3 & $<0.001$ \\
\hline $60-74$ & $9 \cdot 4^{\mathrm{a}}$ & 0.5 & $8 \cdot 2^{b}$ & 0.4 & $8 \cdot 1^{a}$ & 0.5 & $5 \cdot 1^{\mathrm{b}}$ & 0.3 & $<0.001$ \\
\hline$\geq 75$ & $9 \cdot 7^{\mathrm{a}}$ & 0.5 & $7 \cdot 7^{\mathrm{a}}$ & 0.5 & $7 \cdot 3^{a}$ & 0.4 & $4 \cdot 5^{\mathrm{a}}$ & 0.3 & $<0.001$ \\
\hline Fish and shellfish & & & & & & & & & \\
\hline $15-18$ & $3 \cdot 6^{a}$ & 0.4 & $4 \cdot 4^{\mathrm{a}}$ & 0.4 & $3 \cdot 1^{a}$ & 0.3 & $2 \cdot 8^{a}$ & 0.3 & 0.956 \\
\hline $19-59$ & $5 \cdot 9^{\mathrm{a}}$ & 0.5 & $6 \cdot 2^{b}$ & 0.5 & $5 \cdot 6^{\mathrm{b}}$ & 0.5 & $4 \cdot 0^{\mathrm{b}}$ & 0.3 & 0.209 \\
\hline $60-74$ & $7 \cdot 9^{b}$ & 0.6 & $6 \cdot 7^{b}$ & 0.6 & $6 \cdot 4^{\mathrm{b}}$ & 0.5 & $4 \cdot 4^{b}$ & 0.4 & 0.008 \\
\hline$\geq 75$ & $6 \cdot 8^{a}$ & 0.6 & $5 \cdot 9^{a}$ & 0.6 & $5 \cdot 1^{b}$ & 0.5 & $3 \cdot 6^{a}$ & 0.4 & 0.098 \\
\hline Eggs and egg products & & & & & & & & & \\
\hline $15-18$ & $1 \cdot 6^{\mathrm{a}}$ & $0 \cdot 2$ & $1 \cdot 9^{\mathrm{a}}$ & 0.2 & $1 \cdot 2^{a}$ & $0 \cdot 1$ & $1 \cdot 2^{a}$ & 0.1 & 0.778 \\
\hline $19-59$ & $1 \cdot 4^{\mathrm{b}}$ & 0.2 & $2 \cdot 1^{a}$ & 0.2 & $1 \cdot 2^{\mathrm{a}}$ & 0.1 & $1 \cdot 3^{\mathrm{a}}$ & 0.1 & 0.385 \\
\hline $60-74$ & $1 \cdot 7^{\mathrm{a}}$ & 0.2 & $2 \cdot 1^{a}$ & 0.2 & $1 \cdot 3^{a}$ & $0 \cdot 1$ & $1 \cdot 2^{\mathrm{a}}$ & 0.1 & 0.664 \\
\hline$\geq 75$ & $1 \cdot 9^{a}$ & 0.2 & $1 \cdot 4^{\mathrm{b}}$ & 0.2 & $1 \cdot 4^{\mathrm{a}}$ & 0.2 & $0.750^{b}$ & $0 \cdot 101$ & 0.009 \\
\hline
\end{tabular}

a,b,c,d Mean values within a column with unlike superscript letters were significantly different ( $t$ test, ANOVA with Bonferroni correction and Mann-Whitney $U$ test).

${ }^{*}$ Weighted mean of animal protein intake and its percentage.

$\dagger P$ value for mean differences between males and females for animal protein intake (Student's $t$ test and Mann-Whitney $U$ test).

Cereals and cereal products (males: $55 \%$, mean intake of $15.9 \mathrm{~g} / \mathrm{d}$; females: $52 \%$, mean intake of $11.4 \mathrm{~g} / \mathrm{d}$ ) contributed most to the total plant protein intakes followed by potatoes and other tubers, vegetables and fruits.
The consumption of soya proteins was very low $(0 \cdot 174 \mathrm{~g} / \mathrm{d})$. Intakes from potatoes and other tubers, vegetables and fresh fruits were significantly higher in the elderly population (60-74 and $\geq 75$ year groups) than in the 
Table 4. Mean total plant protein intakes and intakes from main sources stratified by age (years) and sex

(Mean values with their standard errors, $n$ 3083)

\begin{tabular}{|c|c|c|c|c|c|c|c|c|c|}
\hline \multirow[b]{3}{*}{ Plant protein food sources } & \multicolumn{4}{|c|}{ Contribution to plant protein intake $(\%)^{*}$} & \multicolumn{5}{|c|}{ Mean plant protein intake $(\mathrm{g} / \mathrm{d})^{\star}$} \\
\hline & \multicolumn{2}{|c|}{ Males } & \multicolumn{2}{|c|}{ Females } & \multicolumn{2}{|c|}{ Males } & \multicolumn{2}{|c|}{ Females } & \multirow[b]{2}{*}{$P \dagger$} \\
\hline & Mean & SEM† & Mean & SEM† & Mean & SEM† & Mean & SEM† & \\
\hline \multicolumn{10}{|l|}{ Total plant protein } \\
\hline $15-18$ & $29^{a}$ & 0.7 & $30^{\mathrm{a}}$ & 0.5 & $23^{a}$ & 0.5 & $18^{\mathrm{a}}$ & 0.4 & $<0.001$ \\
\hline $19-59$ & $28^{a}$ & 0.5 & $28^{b}$ & 0.5 & $25^{a}$ & 0.5 & $18^{\mathrm{a}}$ & 0.4 & $<0.001$ \\
\hline $60-74$ & $27^{\mathrm{a}}$ & 0.5 & $29^{b}$ & 0.5 & $22^{b}$ & 0.4 & $17^{\mathrm{b}}$ & 0.3 & $<0.001$ \\
\hline$\geq 75$ & $28^{a}$ & 0.5 & $26^{c}$ & 0.4 & $20^{\mathrm{c}}$ & 0.4 & $15^{\mathrm{c}}$ & 0.3 & $<0.001$ \\
\hline \multicolumn{10}{|l|}{ Potatoes and other tubers } \\
\hline $15-18$ & $2 \cdot 8^{a}$ & 0.2 & $3 \cdot 1^{a}$ & 0.2 & $2 \cdot 9^{a}$ & 0.1 & $1 \cdot 8^{\mathrm{a}}$ & 0.1 & $<0.001$ \\
\hline $19-59$ & $3 \cdot 4^{\mathrm{b}}$ & 0.2 & $2 \cdot 8^{\mathrm{a}}$ & 0.1 & $2 \cdot 8^{a}$ & 0.1 & $1 \cdot 7^{\mathrm{a}}$ & 0.1 & $<0.001$ \\
\hline $60-74$ & $4 \cdot 4^{\mathrm{c}}$ & 0.1 & $4 \cdot 1^{\mathrm{c}}$ & 0.2 & $3 \cdot 5^{\mathrm{b}}$ & 0.1 & $2 \cdot 4^{\mathrm{b}}$ & 0.1 & $<0.001$ \\
\hline$\geq 75$ & $4 \cdot 8^{\mathrm{C}}$ & 0.2 & $4 \cdot 4^{\mathrm{C}}$ & 0.2 & $3.5^{\mathrm{b}}$ & 0.1 & $2 \cdot 5^{\mathrm{b}}$ & 0.1 & $<0.001$ \\
\hline \multicolumn{10}{|l|}{ Vegetables } \\
\hline $15-18$ & $2 \cdot 1^{\mathrm{a}}$ & 0.1 & $2 \cdot 5^{\mathrm{a}}$ & 0.1 & $1 \cdot 7^{\mathrm{a}}$ & 0.1 & $1 \cdot 5^{\mathrm{a}}$ & 0.1 & 0.153 \\
\hline $19-59$ & $2 \cdot 5^{\mathrm{a}}$ & 0.1 & $3 \cdot 3^{\mathrm{b}}$ & 0.1 & $2 \cdot 1^{\mathrm{b}}$ & 0.1 & $2 \cdot 1^{\mathrm{b}}$ & $0 \cdot 1$ & 0.899 \\
\hline $60-74$ & $2 \cdot 9^{b}$ & 0.1 & $3 \cdot 7^{\mathrm{c}}$ & 0.2 & $2 \cdot 4^{\mathrm{C}}$ & 0.1 & $2 \cdot 3^{b}$ & $0 \cdot 1$ & 0.121 \\
\hline$\geq 75$ & $2 \cdot 9^{b}$ & 0.1 & $3 \cdot 2^{b}$ & 0.1 & $2 \cdot 1^{\mathrm{c}}$ & 0.1 & $1.9^{\mathrm{C}}$ & $0 \cdot 1$ & 0.235 \\
\hline \multicolumn{10}{|c|}{ Legumes (excluding soya products) } \\
\hline $15-18$ & $0 \cdot 116^{a}$ & 0.038 & $0.091^{\mathrm{a}}$ & 0.030 & $0.097^{\mathrm{a}}$ & 0.031 & $0.060^{\mathrm{a}}$ & 0.019 & 0.678 \\
\hline $19-59$ & $0 \cdot 282^{\mathrm{a}}$ & 0.090 & $0.253^{a}$ & 0.079 & $0.255^{a}$ & 0.073 & $0.149^{a}$ & 0.044 & 0.325 \\
\hline $60-74$ & $0.253^{a}$ & 0.064 & $0.170^{a}$ & 0.057 & $0.212^{a}$ & 0.052 & $0.095^{a}$ & 0.032 & 0.129 \\
\hline$\geq 75$ & $0 \cdot 207^{a}$ & 0.061 & $0.149^{a}$ & 0.052 & $0.144^{a}$ & 0.044 & $0.091^{a}$ & 0.033 & 0.572 \\
\hline \multicolumn{10}{|l|}{ Soya products } \\
\hline $15-18$ & $0.125^{a}$ & 0.054 & $0.416^{a}$ & 0.149 & $0.117^{a}$ & 0.051 & $0.265^{a}$ & 0.096 & 0.136 \\
\hline $19-59$ & $0 \cdot 249^{a}$ & 0.080 & $0.387^{a}$ & 0.092 & $0.223^{a}$ & 0.069 & $0.254^{a}$ & 0.063 & 0.098 \\
\hline $60-74$ & $0 \cdot 210^{\mathrm{a}}$ & 0.065 & $0.262^{a}$ & 0.071 & $0.167^{a}$ & 0.052 & $0.148^{a}$ & 0.042 & 0.717 \\
\hline$\geq 75$ & $0.167^{b}$ & 0.067 & $0.104^{b}$ & 0.050 & $0.111^{b}$ & 0.044 & $0.085^{b}$ & 0.047 & 0.646 \\
\hline \multicolumn{10}{|l|}{ Fruits } \\
\hline $15-18$ & $0.828^{a}$ & 0.090 & $2 \cdot 1^{\mathrm{a}}$ & 0.2 & $0.690^{a}$ & 0.079 & $1 \cdot 2^{\mathrm{a}}$ & 0.1 & $<0.001$ \\
\hline $19-59$ & $1 \cdot 4^{\mathrm{b}}$ & 0.1 & $1 \cdot 8^{\mathrm{a}}$ & 0.1 & $1 \cdot 3^{b}$ & 0.1 & $1 \cdot 2^{b}$ & 0.1 & 0.030 \\
\hline $60-74$ & $1 \cdot 6^{\mathrm{c}}$ & 0.1 & $2 \cdot 2^{b}$ & 0.1 & $1 \cdot 3^{\mathrm{C}}$ & 0.1 & $1.4^{\mathrm{C}}$ & $0 \cdot 1$ & 0.005 \\
\hline$\geq 75$ & $1 \cdot 6^{\mathrm{c}}$ & 0.1 & $2 \cdot 0^{\mathrm{b}}$ & 0.1 & $1 \cdot 1^{\mathrm{C}}$ & 0.1 & $1 \cdot 2^{\mathrm{C}}$ & $0 \cdot 1$ & 0.027 \\
\hline \multicolumn{10}{|l|}{ Fresh fruits } \\
\hline $15-18$ & $0.533^{a}$ & 0.054 & $1 \cdot 2^{\mathrm{a}}$ & 0.1 & $0.421^{a}$ & 0.038 & $0.713^{a}$ & 0.046 & $<0.001$ \\
\hline $19-59$ & $0.899^{b}$ & 0.070 & $1 \cdot 3^{a}$ & 0.1 & $0.753^{b}$ & 0.054 & $0.822^{b}$ & 0.041 & $<0.001$ \\
\hline $60-74$ & $1 \cdot 2^{\mathrm{c}}$ & 0.1 & $1.9^{b}$ & 0.1 & $0.927^{c}$ & 0.051 & $1 \cdot 2^{c}$ & 0.1 & 0.001 \\
\hline$\geq 75$ & $1 \cdot 4^{\mathrm{C}}$ & 0.1 & $1.9^{b}$ & 0.1 & $0.993^{c}$ & 0.062 & $1 \cdot 1^{\mathrm{c}}$ & $0 \cdot 1$ & 0.010 \\
\hline \multicolumn{10}{|l|}{ Nuts and seeds } \\
\hline $15-18$ & $0.295^{a}$ & 0.712 & $0.879^{a}$ & 0.198 & $0.269^{a}$ & 0.067 & $0.493^{a}$ & 0.106 & 0.241 \\
\hline $19-59$ & $0.556^{\mathrm{b}}$ & 0.108 & $0.527^{a}$ & 0.112 & $0.522^{b}$ & 0.103 & $0.366^{a}$ & 0.086 & 0.135 \\
\hline $60-74$ & $0.453^{a}$ & 0.119 & $0.271^{a}$ & 0.062 & $0.391^{\mathrm{a}}$ & 0.104 & $0.190^{a}$ & 0.047 & $>0.05$ \\
\hline$\geq 75$ & $0.180^{c}$ & 0.072 & $0.172^{b}$ & 0.084 & $0.149^{c}$ & 0.044 & $0.114^{b}$ & 0.058 & 0.904 \\
\hline \multicolumn{10}{|l|}{ Cereals and cereal products } \\
\hline $15-18$ & $22^{\mathrm{a}}$ & 0.5 & $22^{\mathrm{a}}$ & 0.5 & $18 \cdot 0^{\mathrm{a}}$ & 0.5 & $13 \cdot 2^{\mathrm{a}}$ & 0.3 & $<0.001$ \\
\hline $19-59$ & $20^{b}$ & 0.5 & $19 \cdot 9^{b}$ & 0.4 & $18 \cdot 0^{\mathrm{a}}$ & 0.5 & $12 \cdot 5^{\mathrm{a}}$ & 0.3 & $<0.001$ \\
\hline $60-74$ & $18 \cdot 0^{c}$ & 0.4 & $17 \cdot 2^{\mathrm{C}}$ & 0.5 & $14 \cdot 4^{\mathrm{b}}$ & 0.4 & $10 \cdot 3^{b}$ & 0.3 & $<0.001$ \\
\hline$\geq 75$ & $18 \cdot 4^{\mathrm{c}}$ & 0.4 & $16 \cdot 1^{\mathrm{c}}$ & 0.4 & $13 \cdot 1^{c}$ & 0.3 & $9 \cdot 1^{\mathrm{c}}$ & 0.2 & $<0.001$ \\
\hline
\end{tabular}

${ }^{a, b, c}$ Mean values within a column with unlike superscript letters were significantly different ( $t$ test, ANOVA with Bonferroni correction and Mann-Whitney $U$ test).

${ }^{*}$ Weighted mean of plant protein intake and its percentage.

$\dagger P$ value for mean differences between males and females for plant protein intake (Student's $t$ test and Mann-Whitney $U$ test).

adolescent and adult groups. The latter groups consumed, however, significantly more proteins from cereals and cereal products (data not shown).

\section{Associations between $\mathrm{BMI}$ and animal and plant protein intakes}

The $\chi^{2}$ test showed significant positive linear relationships between BMI and animal protein intake in the elderly group (60-74 years) for both sexes (Table 5). On the other hand, negative associations were observed between BMI and plant protein intakes in the age group of adolescents (15-18 years) and adults (19-59 years) in males and females. Moreover, animal protein intake was not significantly associated with BMI of females and was not retained in the final model.

Associations between waist circumference and animal and plant protein intakes

Table 6 shows the associations between WC and animal and plant protein intakes, which were in line with the observations for BMI. The intake of plant proteins was inversely associated with WC in all sex-age groups, 
Table 5. Generalised linear model for the associations between BMI and animal and plant protein intakes in the sex-age-specific strata

( $\beta$ Coefficients with their standard errors and $95 \%$ confidence interval, $n$ 3054)

\begin{tabular}{|c|c|c|c|c|c|c|}
\hline \multirow[b]{2}{*}{ BMI $\left(\mathrm{kg} / \mathrm{m}^{2}\right)$} & \multicolumn{2}{|c|}{ Coefficients } & \multicolumn{2}{|c|}{$95 \% \mathrm{Cl}$} & \multirow[b]{2}{*}{ Wald $\chi^{2}$} & \multirow[b]{2}{*}{$P$} \\
\hline & $\beta$ & SE & Lower bound & Upper bound & & \\
\hline \multicolumn{7}{|l|}{ Males ( $n$ 1535) } \\
\hline Intercept & 26 & 0.323 & 25 & 26 & 6420 & $<0.001$ \\
\hline Animal protein & 0.013 & 0.004 & 0.005 & 0.021 & $11 \cdot 0$ & 0.001 \\
\hline Plant protein & -0.036 & 0.009 & -0.054 & -0.018 & $15 \cdot 7$ & $<0.001$ \\
\hline \multicolumn{7}{|l|}{ Age (years)* } \\
\hline $15-18$ & -4.3 & 0.261 & $-4 \cdot 8$ & -3.8 & 277 & $<0.001$ \\
\hline $19-59$ & -0.448 & 0.261 & -0.960 & 0.064 & 2.9 & 0.087 \\
\hline $60-74$ & $1 \cdot 1$ & 0.255 & 0.640 & 1.6 & $19 \cdot 9$ & $<0.001$ \\
\hline \multicolumn{7}{|l|}{ Females ( $n$ 1519) } \\
\hline Intercept & 26 & 0.347 & 25 & 26 & 5648 & $<0.001$ \\
\hline Plant protein & -0.046 & 0.014 & -0.073 & -0.018 & $10 \cdot 6$ & 0.001 \\
\hline \multicolumn{7}{|l|}{ Age (years) ${ }^{*}$} \\
\hline $15-18$ & -3.9 & 0.319 & $-4 \cdot 6$ & -3.3 & 152 & $<0.001$ \\
\hline $19-59$ & -1.5 & 0.307 & $-2 \cdot 1$ & -0.899 & 24 & $<0.001$ \\
\hline $60-74$ & $1 \cdot 1$ & 0.310 & 0.474 & 1.7 & $12 \cdot 1$ & $<0.001$ \\
\hline
\end{tabular}

${ }^{*}$ Age ( $\geq 75$ years) reference category.

except for males aged 60-74 years. Animal protein intake was positively associated with males' WC but not with females' WC.

\section{Discussion}

The present findings suggest that in a representative sample of the Belgian population, the most important contributors to animal protein intakes were fresh meat, cheese and milk products. In addition, cereals and cereal products were the most important contributor to plant protein intakes. Other food groups, including soya, contributed to a very low degree to the total plant protein intakes observed.

Given the lack of information on the total protein intakes from previous Belgian national nutrition surveys, we relate the present study findings to those available in other countries including the USA, Europe, Spain and China ${ }^{(41-44)}$.
Differences in study design, food consumption assessment methods and food group classifications used in the various surveys should be taken into consideration when interpreting the relationships. The total energy intakes in Belgian males and females ( 9.5 and $6.6 \mathrm{MJ} / \mathrm{d}$, respectively) were slightly lower than those in the UK population (males: $9.7 \mathrm{MJ} / \mathrm{d}$; females: $6.9 \mathrm{MJ} / \mathrm{d}$ ) and were considerably lower than in the Dutch population (Third Dutch National Food Consumption Survey - 1997/98) (males: 10.8$11.0 \mathrm{MJ} / \mathrm{d}$; females: $7 \cdot 8-8 \cdot 4 \mathrm{MJ} / \mathrm{d})^{(45,46)}$. In addition, the total protein intakes expressed as percentage of energy intake were slightly lower in the Belgian population (males: $15.0 \%$; females: $15.7 \%$ ) than in the UK population (males: 16.5\%; females: 16.6\%). On the other hand, Belgians had similar intakes to the Dutch population (males: 14.7-15.2\%; females: $15 \cdot 6-16 \cdot 6 \%$ ), with the exception of the adolescent age group.

Table 6. Generalised linear model for the associations between waist circumference and animal and plant protein intakes in the sex-age-specific strata

( $\beta$ Coefficients with their standard errors and $95 \%$ confidence intervals, $n$ 2874)

\begin{tabular}{|c|c|c|c|c|c|c|}
\hline \multirow[b]{2}{*}{ Waist circumference (cm) } & \multicolumn{2}{|c|}{ Coefficients } & \multicolumn{2}{|c|}{$95 \% \mathrm{Cl}$} & \multirow[b]{2}{*}{ Wald $\chi^{2}$} & \multirow[b]{2}{*}{$P$} \\
\hline & $\beta$ & SE & Lower bound & Upper bound & & \\
\hline \multicolumn{7}{|l|}{ Males $(n 1450)$} \\
\hline Intercept & 102 & 1.0 & 100 & 104 & 9588 & $<0.001$ \\
\hline Animal protein & 0.041 & 0.013 & 0.015 & 0.066 & $9 \cdot 8$ & 0.002 \\
\hline Plant protein & -0.137 & 0.030 & -0.195 & -0.079 & 21 & $<0.001$ \\
\hline \multicolumn{7}{|l|}{ Age (years) $)^{\star}$} \\
\hline $15-18$ & -20 & 0.839 & -22 & $-18 \cdot 4$ & 572 & $<0.001$ \\
\hline $19-59$ & -7.9 & 0.845 & $-9 \cdot 6$ & $-6 \cdot 2$ & 88 & $<0.001$ \\
\hline $60-74$ & 0.397 & 0.826 & $-1 \cdot 2$ & $2 \cdot 0$ & 0.231 & 0.631 \\
\hline \multicolumn{7}{|l|}{ Females ( $n$ 1424) } \\
\hline Intercept & 96 & $1 \cdot 1$ & 94 & 99 & 8145 & $<0.001$ \\
\hline Plant protein & -0.096 & 0.043 & -0.180 & -0.013 & $5 \cdot 1$ & 0.024 \\
\hline \multicolumn{7}{|l|}{ Age (years) ${ }^{*}$} \\
\hline $15-18$ & $-18 \cdot 6$ & 0.972 & -20 & $-16 \cdot 7$ & 365 & $<0.001$ \\
\hline $19-59$ & $-11 \cdot 8$ & 0.950 & $-13 \cdot 6$ & -9.9 & 154 & $<0.001$ \\
\hline $60-74$ & $-2 \cdot 3$ & 0.951 & -4.2 & -0.478 & $6 \cdot 1$ & 0.014 \\
\hline
\end{tabular}

${ }^{*}$ Age ( $\geq 75$ years) reference category. 
We have also compared the present findings with the results of the Third US National Health and Nutrition Examination Survey (1988-91) ${ }^{(43)}$ and the Spanish Catalan Nutritional Survey $(2002-3)^{(42)}$, which used the same dietary assessment methods. It was observed that the total energy intakes of the Belgian population were lower than those of the US population (males: $10 \cdot 8 \mathrm{MJ} / \mathrm{d}$; females: $7 \cdot 3 \mathrm{MJ} / \mathrm{d}$ ). Belgian males and elderly females (60-75 years), however, had higher total energy intakes than the Spanish (males: $9 \cdot 0 \mathrm{MJ} / \mathrm{d}$; females: $5 \cdot 7 \mathrm{MJ} / \mathrm{d}$ ).

\section{Total protein, animal protein and plant protein intakes}

According to the present study, total protein intakes were lower in the Belgian population, especially in males, when compared with US males and females $(97$ and $65 \mathrm{~g} / \mathrm{d}$, respectively) ${ }^{(43)}$ and with Spanish males and females (97 and $79 \mathrm{~g} / \mathrm{d}$, respectively) ${ }^{(42)}$ presumably due to lower intakes of animal protein. Protein intakes expressed as percentage of energy intake among Belgian sex-age-specific groups were rather similar to US adults and the elderly population (males: $15 \cdot 0-16 \cdot 0 \%$; females: $15 \cdot 0-17 \cdot 0 \%$ ), but lower than those observed in Spanish sex-age groups (males: 18.9\%; females: $19.4 \%$ ). The Belgian population, with the exception of participants in the $\geq 75$ years age category, however, had higher total protein, animal protein and plant protein intakes than average intakes of the European Prospective Investigation into Cancer and Nutrition Potsdam Study participants (total protein: $70 \mathrm{~g} / \mathrm{d}$; animal protein: $44 \mathrm{~g} / \mathrm{d}$; plant protein: $24 \mathrm{~g} / \mathrm{d})^{(47)}$.

Compared with the US survey, the Belgian population had lower protein intakes from milk, yogurt, and eggs and egg products than the US population (milk and yogurt: $11.3 \%$ in males and $13.4 \%$ in females; eggs and egg products: $4.1 \%$ in males and $4.3 \%$ in females). The present results showed that fish and shellfish, and cheese contributed more to the total protein intakes in the Belgian population than in the US population. More specifically, participants in the age groups of 60-74 years and $\geq 75$ years consumed approximately twice as much fish-derived proteins than their US counterparts (males: 5.3\%; females: 5.6\%). On the other hand, fish proteins contributed more to total protein intakes in Spain (14.7\%) than in Belgium (males: 3.6-7.9\%; females: 4.4-6.7\%). In contrast, meat and meat products contributed less to animal intakes in the Belgian population (males: 36-37\%; females: $30-36 \%)$ than in the Spanish (39.4\%).

It was also observed that the consumption of meat proteins from subgroups including fresh meat, poultry and processed meat was lower among the Belgian than the Spanish population; females, in particular, had lower intakes of the above-mentioned meat subgroups. For example, protein intakes from poultry were much lower among Belgians (males: 7.0-8.1\%; females: 7.5-8.9\%) than among Spanish (14.0\%). In addition, dairy and egg protein intakes were slightly higher among the Spanish population ( 12.5 and $3 \cdot 1 \%$, respectively).
Fresh fruits contributed less to the total protein intakes in the Belgian population (males: 0.533-1.4\%; females: $1.2-$ $1.9 \%$ ) than in the US population (males: $1.4 \%$; females: $1.8 \%$ ) and in the Spanish population (2.0\%). Protein intakes from legumes in the Belgian population were also lower than both the US (males: $2 \cdot 3 \%$; females: $2 \cdot 1 \%$ ) and the Spanish population $(2 \cdot 1 \%)$. Plant protein intake from vegetables in the present study population (males: $2 \cdot 1-2.9 \%$; females: $2 \cdot 5-3.7 \%$ ) was much lower than in the US population (males: $7 \cdot 7 \%$, females: $8.7 \%$ ), but higher than in the Spanish population (2.3\%). On the other hand, higher amounts of plant proteins from cereals and cereal products were consumed by the Belgian population in all sex-age-specific groups in comparison with the US (males: 18.0\%; females: 18.1\%) and the Spanish populations (13.0\%).

Soya protein intakes were separately analysed in the present study, as soyabeans are rich sources of protein $(35-49 \%)$ and of essential amino acids ${ }^{(48,49)}$. The analysis suggested that the consumption of the Belgian population was very low and lower than those of the Chinese Guangzhou populations (males: $0 \cdot 111-0.228$ and $3.6 \mathrm{~g} / \mathrm{d}$; females: $0.085-0 \cdot 271$ and $4 \cdot 1 \mathrm{~g} / \mathrm{d}$, respectively) ${ }^{(44)}$ and of other East Asian populations $(2 \cdot 0-9.6 \mathrm{~g} / \mathrm{d}$, soya protein:total protein ratio: $3 \cdot 5-15 \cdot 3 \%)^{(50)}$. This finding is supported by the European Prospective Investigation into Cancer and Nutrition study, which found that soya product intakes were low across all ten participating European countries ${ }^{(41)}$

\section{$B M I$ and animal and plant protein intake}

The present results showed that animal protein intakes were positively associated with BMI of males, whereas plant protein intakes were inversely associated with the BMI of both sexes. After adjustment for potential confounders, these associations remained statistically significant. Others have reported similar results ${ }^{(7,51)}$. Hermanussen ${ }^{(51)}$ concluded that the BMI of German male and female adolescents showed significant positive associations with total protein $(r 0.143 ; P<0.0001)$ and animal protein intakes $(r 0.151 ; P<0.0001)$. Plant protein intakes in the study of Mahon et $a l^{(7)}$ were inversely associated with the BMI of the US OW post-menopausal women.

Other studies have, however, suggested an inverse relationship between both plant and animal protein intakes and $\mathrm{BMI}^{(52,53)}$, which are supported by some separate studies on animal protein intake ${ }^{(51,54,55)}$ and plant protein intake ${ }^{(11,56-59)}$. In relation to animal protein intake, some studies have reported different results ${ }^{(7,60)}$. Umesawa et $a l .{ }^{(60)}$, for instance, found no association between BMI and animal protein intake, while BMI decreased slightly when females increased their animal protein consumption. Two ${ }^{(60,61)}$ similar studies have reported that plant proteinbased diets had no significant effect on the BMI of East Asian and Western populations. 


\section{Waist circumference and animal and plant protein intake}

The WHO guidelines state that risks for metabolic complications increase in men with a WC $\geq 102 \mathrm{~cm}$ and in women with a $\mathrm{WC} \geq 88 \mathrm{~cm}^{(62)}$. Although the Belgian population had WC values below these cut-offs, the results of the present study indicate that Belgian females and the elderly in particular are at higher risk of being OW and obese.

The present findings also suggest that animal protein intakes might result in an increased WC for males, and plant protein intakes decrease in both males and females. This is in line with the observations that plant-based protein diets, compared with animal-based protein diets, have an inverse impact on WC of obese subjects ${ }^{(11,63)}$. For example, the results of a randomised controlled clinical trial on OW and obese people suggested that soya proteinbased diets resulted in bigger reductions in participants' WC than those not consuming soya protein-based diets $^{(11)}$. Other studies ${ }^{(27,52,64,65)}$ have, however, reported the opposite. For instance, a randomised trial involving obese adults reported no significant difference between the effect of animal protein and plant protein on WC, with total protein intakes significantly lowering the WC $(P<0.05)^{(52)}$. Hence, the results of randomised trials indicate that plant protein-based diets have a more protective effect against $\mathrm{OB}$ than animal protein-based diets ${ }^{(52,64,66)}$. Recent studies have, however, suggested that the negative relationship between animal protein and BMI refers only to OW and obese individuals and does not affect individuals with a normal $\mathrm{BMI}^{(26,67,68)}$.

The mechanisms that relate animal and plant protein intakes with BMI and WC are unclear. One proposed mechanism is that animal proteins from beef, pork and poultry provide an important amount of energy and are positively associated with cholesterol and SFA intakes. Therefore, animal protein intake may result in an increase in BMI and the risk of OW and OB. The intake of plant proteins, conversely, is considered an important factor to control body weight and improved body composition and blood lipid profiles because of their associations with lower intakes of energy, total fat, cholesterol and SFA, and higher PUFA:SFA ratios ${ }^{(16,69,70)}$.

\section{Strengths and limitations of the study}

This nutrition survey was representative for the Belgian population. One of the limitations of the present study is the use of self-reported body composition variables including weight and height. However, WC was measured by trained dietitians. Furthermore, the present study did not consider physical activity and energy expenditure, factors that could have an effect on the observed associations. Information on food intake was collected via two nonconsecutive $24 \mathrm{~h}$ recalls, which allows statistical adjustments for within-person variability. Yet, one of the limitations of the $24 \mathrm{~h}$ recall method is that it does not allow quantifying proportions of non-consumers for particular food items, a fortiori for infrequently consumed foods. Moreover, information on the food consumption relies on individuals' memory and might therefore be biased towards misreporting. Additionally, underestimation or overestimation of portion sizes could result in inaccurate associations between dietary intake and body composition.

\section{Conclusion}

The results of the present study suggest that meat protein contributed most to animal protein intakes, and cereals and cereal products contributed to plant protein intakes. Animal and plant protein intakes were significantly different between males and females, and intakes decreased with age in both sexes. It was also observed that the consumption of legume- and soya-derived protein was very low in Belgium. Furthermore, the results indicated that animal protein intake was positively associated with BMI and WC of males, while plant protein intake was found to be negatively associated with BMI and WC of the whole population. The present study findings indicate that the intakes of plant protein could offer a potential protective effect against OW and OB.

\section{Acknowledgements}

The authors would like to acknowledge Mr Paul Bahta for the English proofreading of the manuscript. This study was supported by the ALPRO Foundation. The food consumption survey was funded by the Federal Ministry of Health, Food Chain Safety and Environment. Y. L. performed and interpreted the statistical analyses and drafted the manuscript. A. P. and M. D. N., the dietitians of our team, were responsible for the data linking with the food composition databases. S. D. V., H. V. O. and I. H. were responsible for the coordination of the fieldwork of the Belgian food consumption survey, and G. D. B. and S. D. $\mathrm{H}$. were involved in the conceptualisation of the national food consumption survey. All other authors helped in the evaluation of the results and in the writing of the manuscript. All authors have evaluated and approved the final version of the manuscript. The authors declare no conflicts of interest.

\section{References}

1. Foreyt JP, Salas-Salvado J, Caballero B, et al. (2009) Weightreducing diets: are there any differences? Nutr Rev 67, Suppl. 1, S99-S101.

2. Wolfe RR, Miller SL \& Miller KB (2008) Optimal protein intake in the elderly. Clin Nutr 27, 675-684.

3. Abete I, Parra D \& Martinez JA (2009) Legume-, fish-, or high-protein-based hypocaloric diets: effects on weight loss and mitochondrial oxidation in obese men. J Med Food 12, 100-108. 
4. Appel LJ (2003) The effects of protein intake on blood pressure and cardiovascular disease. Curr Opin Lipidol 14, 55-59.

5. Bortolotti M, Kreis R, Debard C, et al. (2009) High protein intake reduces intrahepatocellular lipid deposition in humans. Am J Clin Nutr 90, 1002-1010.

6. Dewell A, Weidner G, Sumner MD, et al. (2007) Relationship of dietary protein and soy isoflavones to serum IGF-1 and IGF binding proteins in the Prostate Cancer Lifestyle Trial. Nutr Cancer 58, 35-42.

7. Mahon AK, Flynn MG, Stewart LK, et al. (2007) Protein intake during energy restriction: effects on body composition and markers of metabolic and cardiovascular health in postmenopausal women. J Am Coll Nutr 26, 182-189.

8. Thorpe DL, Knutsen SF, Beeson WL, et al. (2008) Effects of meat consumption and vegetarian diet on risk of wrist fracture over 25 years in a cohort of peri- and postmenopausal women. Public Health Nutr 11, 564-572.

9. Tseng M, Byrne C, Evers KA, et al. (2007) Dietary intake and breast density in high-risk women: a cross-sectional study. Breast Cancer Res 9, R72.

10. Westerterp-Plantenga MS (2008) Protein intake and energy balance. Regul Pept 149, 67-69.

11. Allison DB, Gadbury G, Schwartz LG, et al. (2003) A novel soy-based meal replacement formula for weight loss among obese individuals: a randomized controlled clinical trial. Eur J Clin Nutr 57, 514-522.

12. Ashton EL, Dalais FS \& Ball MJ (2000) Effect of meat replacement by tofu on CHD risk factors including copper induced LDL oxidation. J Am Coll Nutr 19, 761-767.

13. Carroll KK \& Kurowska EM (1995) Soy consumption and cholesterol reduction: review of animal and human studies. J Nutr 125, 594S-597S.

14. Jenkins DJ, Kendall CW, Vidgen E, et al. (2001) High-protein diets in hyperlipidemia: effect of wheat gluten on serum lipids, uric acid, and renal function. Am J Clin Nutr 74, 57-63.

15. Jenkins DJ, Kendall CW, Faulkner DA, et al. (2008) Long-term effects of a plant-based dietary portfolio of cholesterol-lowering foods on blood pressure. Eur J Clin Nutr 62, 781-788.

16. Jenkins DJ, Wong JM, Kendall CW, et al. (2009) The effect of a plant-based low-carbohydrate ("Eco-Atkins") diet on body weight and blood lipid concentrations in hyperlipidemic subjects. Arch Intern Med 169, 1046-1054.

17. Li Z, Aronson WJ, Arteaga JR, et al. (2008) Feasibility of a low-fat/high-fiber diet intervention with soy supplementation in prostate cancer patients after prostatectomy. Eur J Clin Nutr 62, 526-536.

18. Newton KM, LaCroix AZ, Levy L, et al. (2006) Soy protein and bone mineral density in older men and women: a randomized trial. Maturitas 55, 270-277.

19. Wu AH, Stanczyk FZ, Martinez C, et al. (2005) A controlled 2-mo dietary fat reduction and soy food supplementation study in postmenopausal women. Am J Clin Nutr 81, 1133-1141.

20. Krajcovicova-Kudlackova M, Babinska K \& Valachovicova M (2005) Health benefits and risks of plant proteins. Bratisl Lek Listy 106, 231-234.

21. Allen NE, Key TJ, Appleby PN, et al. (2008) Animal foods, protein, calcium and prostate cancer risk: the European Prospective Investigation into Cancer and Nutrition. Br J Cancer 98, 1574-1581.

22. Duc Son le NT, Hanh TT, Kusama K, et al. (2005) Anthropometric characteristics, dietary patterns and risk of type 2 diabetes mellitus in Vietnam. J Am Coll Nutr 24, 229-234.

23. Lee YM, Skurk T, Hennig M, et al. (2007) Effect of a milk drink supplemented with whey peptides on blood pressure in patients with mild hypertension. Eur J Nutr 46, 21-27.
24. Sieri S, Krogh V, Muti P, et al. (2002) Fat and protein intake and subsequent breast cancer risk in postmenopausal women. Nutr Cancer 42, 10-17.

25. Aoe S, Koyama T, Toba Y, et al. (2005) A controlled trial of the effect of milk basic protein (MBP) supplementation on bone metabolism in healthy menopausal women. Osteoporos Int 16, 2123-2128.

26. Farnsworth E, Luscombe ND, Noakes M, et al. (2003) Effect of a high-protein, energy-restricted diet on body composition, glycemic control, and lipid concentrations in overweight and obese hyperinsulinemic men and women. $A m \mathrm{~J}$ Clin Nutr 78, 31-39.

27. Ouellet V, Marois J, Weisnagel SJ, et al. (2007) Dietary cod protein improves insulin sensitivity in insulin-resistant men and women: a randomized controlled trial. Diabetes Care 30, 2816-2821.

28. De Vriese S, De Backer G, De Henauw S, et al. (2005) The Belgian food consumption survey: aims, design and methods. Arch Public Health 63, 1-16.

29. Brussaard JH, Johansson L \& Kearney J (2002) Rationale and methods of the EFCOSUM project. Eur J Clin Nutr 56, Suppl. 2, S4-S7.

30. Slimani N \& Valsta L (2002) Perspectives of using the EPIC-SOFT programme in the context of pan-European nutritional monitoring surveys: methodological and practical implications. Eur J Clin Nutr 56, Suppl. 2, S63-S74.

31. NUBEL (2004) Belgium Food Composition Table, 4th ed. Brussels: Ministry of Public Health (in Dutch).

32. NEVO (2001) NEVO-Table, Dutch Food Composition Table 2001. Zeist: NEVO Foundation (in Dutch).

33. US Department of Agriculture (USDA) (2009) The USDA National Nutrient Database for Standard Reference. http://www.nal.usda.gov/fnic/foodcomp/search/ (accessed June 2009).

34. FDA (Food and Drug Administration) (2009) Soy protein and risk of coronary heart disease. http://www.fda.gov/ Food/LabelingNutrition/LabelClaims/HealthClaimsMeeting SignificantScientificAgreementSSA/ucm074740.htm (accessed December 2009).

35. World Health Organization (WHO) (2007) Body mass index (BMI). http://www.euro.who.int/nutrition/20030507_1 (accessed October 2009).

36. Vrije Universiteit Brussel, Antropogenetica, Katholieke Universiteit Leuven, \& Jeugdgezondheidszorg (2004) Growth charts, Flanders. http://www.vub.ac.be/groeicurven/english. html (accessed December 2009).

37. Cole TJ, Bellizzi MC, Flegal KM, et al. (2000) Establishing a standard definition for child overweight and obesity worldwide: international survey. BMJ 320, 1240-1243.

38. Lean ME, Han TS \& Morrison CE (1995) Waist circumference as a measure for indicating need for weight management. BMJ 311, 158-161.

39. Taylor RW, Jones IE, Williams SM, et al. (2000) Evaluation of waist circumference, waist-to-hip ratio, and the conicity index as screening tools for high trunk fat mass, as measured by dual-energy X-ray absorptiometry, in children aged 3-19 y. Am J Clin Nutr 72, 490-495.

40. WHO (2002) Population nutrient intake goals for preventing diet-related chronic diseases. http://www.who.int/nutrition/ topics/5_population_nutrient/en/o (accessed December 2009).

41. Keinan-Boker L, Peeters PH, Mulligan AA, et al. (2002) Soy product consumption in 10 European countries: the European Prospective Investigation into Cancer and Nutrition (EPIC) study. Public Health Nutr 5, 1217-1226.

42. Serra-Majem L, Ribas-Barba L, Salvador G, et al. (2007) Trends in energy and nutrient intake and risk of inadequate 
intakes in Catalonia, Spain (1992-2003). Public Health Nutr 10, $1354-1367$

43. Smit E, Nieto FJ, Crespo CJ, et al. (1999) Estimates of animal and plant protein intake in US adults: results from the Third National Health and Nutrition Examination Survey, 19881991. J Am Diet Assoc 99, 813-820.

44. Zhang B, Chen YM, Huang LL, et al. (2008) Greater habitual soyfood consumption is associated with decreased carotid intima-media thickness and better plasma lipids in Chinese middle-aged adults. Atherosclerosis 198, 403-411.

45. Hulshof KF, Brussaard JH, Kruizinga AG, et al. (2003) Socioeconomic status, dietary intake and 10 y trends: the Dutch National Food Consumption Survey. Eur J Clin Nutr 57, $128-137$.

46. Swan G (2004) Findings from the latest National Diet and Nutrition Survey. Proc Nutr Soc 63, 505-512.

47. Weikert C, Walter D, Hoffmann K, et al. (2005) The relation between dietary protein, calcium and bone health in women: results from the EPIC-Potsdam cohort. Ann Nutr Metab 49, 312-318.

48. Torres N, Torre-Villalvazo I \& Tovar AR (2006) Regulation of lipid metabolism by soy protein and its implication in diseases mediated by lipid disorders. J Nutr Biochem 17, $365-373$

49. Velasquez MT \& Bhathena SJ (2007) Role of dietary soy protein in obesity. Int J Med Sci 4, 72-82.

50. Messina M, Nagata C \& Wu AH (2006) Estimated Asian adult soy protein and isoflavone intakes. Nutr Cancer 55, $1-12$.

51. Hermanussen M (2008) Nutritional protein intake is associated with body mass index in young adolescents. Georgian Med News 156, 84-88.

52. Liao FH, Shieh MJ, Yang SC, et al. (2007) Effectiveness of a soy-based compared with a traditional low-calorie diet on weight loss and lipid levels in overweight adults. Nutrition 23, 551-556.

53. Yamashita T, Sasahara T, Pomeroy SE, et al. (1998) Arterial compliance, blood pressure, plasma leptin, and plasma lipids in women are improved with weight reduction equally with a meat-based diet and a plant-based diet. Metabolism 47, 1308-1314.

54. Benito-Garcia E, Feskanich D, Hu FB, et al. (2007) Protein, iron, and meat consumption and risk for rheumatoid arthritis: a prospective cohort study. Arthritis Res Ther 9, R16.

55. Xu F, Yin XM \& Tong SL (2007) Association between excess bodyweight and intake of red meat and vegetables among urban and rural adult Chinese in Nanjing, China. Asia Pac J Public Health 19, 3-9.

56. Alewaeters K, Clarys P, Hebbelinck M, et al. (2005) Crosssectional analysis of BMI and some lifestyle variables in
Flemish vegetarians compared with non-vegetarians. Ergonomics 48, 1433-1444.

57. Barnard ND, Katcher HI, Jenkins DJ, et al. (2009) Vegetarian and vegan diets in type 2 diabetes management. Nutr Rev 67, 255-263.

58. Nakamoto K, Watanabe S, Kudo H, et al. (2008) Nutritional characteristics of middle-aged Japanese vegetarians. $J$ Atheroscler Thromb 15, 122-129.

59. Perez-Guisado J, Munoz-Serrano A \& Alonso-Moraga A (2008) Spanish Ketogenic Mediterranean Diet: a healthy cardiovascular diet for weight loss. Nutr J 7, 30.

60. Umesawa M, Sato S, Imano H, et al. (2009) Relations between protein intake and blood pressure in Japanese men and women: the Circulatory Risk in Communities Study (CIRCS). Am J Clin Nutr 90, 377-384.

61. Sites CK, Cooper BC, Toth MJ, et al. (2007) Effect of a daily supplement of soy protein on body composition and insulin secretion in postmenopausal women. Fertil Steril 88, $1609-1617$.

62. WHO (2009) General strategies for obesity prevention. http:// www.who.int/nutrition/topics/5_population_nutrient/en/ index 5. html (accessed December 2009).

63. Konig D, Deibert P, Frey I, et al. (2008) Effect of meal replacement on metabolic risk factors in overweight and obese subjects. Ann Nutr Metab 52, 74-78.

64. Hermansen K, Sondergaard M, Hoie L, et al. (2001) Beneficial effects of a soy-based dietary supplement on lipid levels and cardiovascular risk markers in type 2 diabetic subjects. Diabetes Care 24, 228-233.

65. Nakamura Y, Ueno Y, Tamaki S, et al. (2007) Fish consumption and early atherosclerosis in middle-aged men. Metabolism 56, 1060-1064.

66. Hoie LH, Morgenstern EC, Gruenwald J, et al. (2005) A double-blind placebo-controlled clinical trial compares the cholesterol-lowering effects of two different soy protein preparations in hypercholesterolemic subjects. Eur J Nutr $\mathbf{4 4}$, $65-71$.

67. Abete I, Parra D, Crujeiras AB, et al. (2008) Specific insulin sensitivity and leptin responses to a nutritional treatment of obesity via a combination of energy restriction and fatty fish intake. J Hum Nutr Diet 21, 591-600.

68. Bellissimo N, Desantadina MV, Pencharz PB, et al. (2008) A comparison of short-term appetite and energy intakes in normal weight and obese boys following glucose and whey-protein drinks. Int J Obes (Lond) 32, 362-371.

69. Berkow SE \& Barnard N (2006) Vegetarian diets and weight status. Nutr Rev 64, 175-188.

70. Gardner CD, Coulston A, Chatterjee L, et al. (2005) The effect of a plant-based diet on plasma lipids in hypercholesterolemic adults: a randomized trial. Ann Intern Med 142, 725-733. 